\title{
Analysis of food advertising to children on Spanish television: probing exposure to television marketing
}

Daniel Campos ${ }^{1}$, Juan José Hernández-Torres², Ahmad Agil ${ }^{3}$, Mariano Comino ${ }^{1}$, Juan Carlos López ${ }^{1}$, Victoria Macías ${ }^{1}$, Cristina Campoy ${ }^{1,4}$

\author{
${ }^{1}$ EURISTIKOS Excellence Centre for Paediatric Research, University of Granada, \\ Granada, Spain \\ ${ }^{2}$ University Hospital San Rafael, Granada, Spain \\ ${ }^{3}$ Department of Pharmacology, University of Granada, Granada, Spain \\ ${ }^{4}$ Department of Paediatrics, University of Granada, Granada, Spain
}

Submitted: 21 April 2014

Accepted: 6 October 2014

Arch Med Sci 2016; 12, 4: 799-807

DOI: 10.5114 /aoms.2016.60969

Copyright (C 2016 termedia \& Banach

\section{Abstract}

Introduction: We aimed to assess longitudinal changes in television (TV) food advertising during 2013 compared to 2007, measuring children's exposure to healthy and unhealthy advertisements, after the new European and Spanish Public Health laws published in 2011.

Material and methods: Two thematic channels for children (TC), and 2 generalist channels (GC) for all ages were recorded, between April and May 2013, on 2 week and 2 weekend days. Food advertisements were classified as core (CFA) (nutrient dense, low energy), non-core (NCFA) (unbalanced energy profile or high in energy), or others (OFA) (supermarkets and special food).

Results: One thousand two hundred sixty-three food advertisements were recorded (TC: $579 /$ GC: 684 ) in 2013 . NCFA were the most shown $(54.9 \%)$ in the regular full day TV programming $(p<0.001)$. In 2013, children watching GC had a higher relative risk of being exposed to fast food advertisements than when watching TC ( $R R=2.133,95 \% \mathrm{Cl}: 1.398-3.255)$; CFA were broadcast most frequently in 2013 (GC: $23.7 \%$; and TC: 47.2\%) vs. 2007 (TC: $22.9 \%)(p<0.001)$. The proportion of broadcasting between NCFA/CFA and OFA food advertisements in children's peak time slots was higher on TC (203/162) during 2013 than on GC (189/140), and significantly higher than that shown on TC in $2007(180 / 36, p<0.001)$.

Conclusions: Broadcasting of unhealthy TV food advertising on TC is lower today than six years ago; but, children's exposure to TV advertising of unhealthy food is worrying in Spain, and there is more exposure to unhealthy than healthy food by TV. Watching GC in 2013 had higher risk of being exposed to fast food advertisements than watching TC.

Key words: childhood obesity, food publicity, policy food, television marketing.

\section{Introduction}

\section{Obesity as a public health problem}

In consumer society, obesity has become a serious epidemic for public health in the $21^{\text {st }}$ century. There are multiple risk factors influencing this, such as a sedentary lifestyle and poor diet, which cause an energy imbal-

\author{
Corresponding author: \\ Prof. Cristina Campoy MD \\ Department of Paediatrics \\ School of Medicine \\ University of Granada \\ Avda. De Madrid 11 \\ 18012-Granada, Spain \\ Phone: +34607631601 \\ E-mail: ccampoy@ugr.es
}


ance. Adding to this, a new obesity risk factor has been detected - the misuse of food advertising [1].

Childhood obesity is also one of the most serious public health challenges. In 2012, more than 40 million children under the age of 5 were overweight or obese. Once considered a high-income country problem, overweight and obesity are now on the rise in low and middle income countries as well, particularly in urban settings. In developing countries with emerging economies (classified by the World Bank as lower and middle income countries) the prevalence of childhood overweight and obesity in preschool children is in excess of $30 \%$. More than 30 million overweight children are living in developing countries and 10 million in developed countries [2, 3].

In 2012, according to the Centers for Disease Control and Prevention (CDC), $8.1 \%$ of infants and toddlers had high weight for recumbent length, and $16.9 \%$ of 2 to 19 year olds and $34.9 \%$ of adults (age adjusted) aged 20 years or older were obese [4]. Changes in obesity prevalence from the 1960s show a rapid increase in the 1980s and 1990s, when obesity prevalence among children and teens tripled, from nearly $5 \%$ to approximately $15 \%$ [5]. Data for the Spanish population show an alarming prevalence of obesity in children of ages 2 to $5(11.1 \%)$, ages 6 to $9(15.9 \%)$ and ages 10 to $13(16.6 \%)$ [6].

\section{Advertising exposure in childhood}

Marketing food to children has been the subject of widespread discussion in the European Consumers' Organization, and an association has been found between watching TV and childhood obesity [7]. In 2005, a European childhood obesity project coordinated by the European Heart Network was carried out. This research produced a report, Marketing of Unhealthy Food to Children in Europe, which concluded that most of the food shown to children in Europe was regarded as 'unhealthy', with television as the prime medium for such advertising, although in-school and internet marketing were growing [8].

Reference studies confirm an association between the broadcasting frequency of non-core food advertisement (NCFA) and the prevalence of obesity in childhood; therefore, food advertising may play an important role in this disease [9]. Children aged from 8 to 18 make use of multiple types of media resources (often simultaneously) and spend more time (44.5 h/week) in front of the computer, television (TV), and game screens than in any other activity in their lives, except for sleeping. Furthermore, also researchers have found a strong association between the increase in non-core food advertising and rates of childhood obesity [10]. Most children under 6 years old cannot distinguish between programming and advertising, and children less than 8 years old do not understand the persuasive intention of marketing messages. Publicity, when designed for the children's market, is, by definition, very exploitative. Children have a remarkable ability to recall content from adverts to which they have been exposed. Product preference has been shown to occur with only a single commercial exposure and to strengthen with repeated exposures. Product preferences affect children's requests and consequently influence parents' purchasing decisions [11].

\section{Neuromarketing and food choices}

A variety of sensory stimuli, emotional states and feelings contribute to pleasant sensations, specifically during the post-consumption phase, when nutrients interact with sensors in the gastrointestinal tract, other peripheral organs and the brain itself. The question is, would it be possible for people to feel the same when watching food advertising on TV? [12].

Several studies emphasize the difficulties involving choice making and the importance of emotional and social factors. There are some remarkable results which indicate an association of pleasure and rewarding experiences [13] with the activation of specific brain areas. These areas were also studied in previous investigations [14], showing that highly appreciated items trigger stronger activation than the reaction generated by less appreciated products. Other studies indicate that this relationship between stimuli and neural reactions is highly modulated by emotions [15].

\section{Food advertising to children: the global regulatory environment}

Globally successful companies have increased their product sales by using suitable marketing. However, healthy food consumption campaigns by public health organizations do not achieve the same success.

Recent and emerging neuroscience and psychological studies on adolescents suggest a need to review the traditional approach to publicity regulation [16]. It is necessary to work together in order to solve the overweight and obesity epidemic in childhood and to prevent secondary diseases. In the face of rising obesity levels across Europe, in 2011 new European and Spanish public health laws aimed to protect children from the influence of 'unhealthy' food marketing [17], focusing efforts on reducing excessive weight gain, through the promotion of active and healthy life styles in children, including moderate TV viewing, regular family meal times and frequent exercise 
to strengthen physical and psychological well being in children and teenagers [7, 18-20]; however, few countries have introduced efficient policies to address this [8].

The aim of this study was to assess longitudinal changes in food advertising since 2007 in Spain, measuring children's current exposure to healthy and unhealthy food advertisements on TV, on thematic channels for children (TC) and generalist channels (GC), and analyse the nature of broadcasting in children's peak time slots. We also aimed to investigate whether the current publicity in Spain for children's audiences is more suitable and optimal than 6 years ago, if so, demonstrating that the Spanish laws are really contributing to a positive effect on food advertising for children, and, as a result on their health.

\section{Material and methods}

\section{Study design and methodology}

Since the studies on Spanish TV Marketing in 2007 [21], a total of $256 \mathrm{~h}$ have been recorded from the two Spanish channels most watched by children aged 2-12 years (Boing and Disney Channel), and two Spanish channels directed at all ages (Antena 3 and La Sexta), between April and May 2013. Two weekdays and 2 weekend days, from 6:00 to 22:00, were recorded.

The register was taken by a nutritionist who is specialised in marketing. This researcher was previously trained to classify the different types of advertisements according to their quantity of nutrients, subliminal messages, and their recommendations about healthy habits [21]. The software Longo Macth v. 0.16.5 was used to analyse the recordings.

Food advertisements were classified as core (CFA) (nutrient dense, low in energy), NCFA (unbalanced energy profile or high in energy), or other food advertisement (OFA) (supermarkets and special food). It was also analysed whether advertisements were shown in children's peak time slots (7:00-8:59 and 15:30-22:00 on weekdays, and 7:30-10:29 and 15:30-22:00 on weekend days) or children's nonpeak time slots (9:0015:29 on weekdays and 10:30-15:29 on weekend days) [22].

Data were registered with a recorder model Ciga HD 2TB. It was programmed to record 4 successive days ( 2 on weekdays and 2 on weekend days) in the time slot previously detailed.

The broadcast ratio of food advertisements $(x)$ in different time slots was calculated as the quotient of the sum of total frequency of advertisements shown in a specific time slot during the 4 days registered ( 2 weekdays and 2 weekend days) and the total hours of this time slot. Total time reg- istered in children's peak time slots (y) was $36 \mathrm{~h}$ and 24 in children's nonpeak time slots (z).

$$
\begin{aligned}
& x=\frac{\sum \text { frequency of food advertisements }}{h} \\
& y=\frac{\sum \text { frequency of food advertisements }}{36} \\
& z=\frac{\sum \text { frequency of food advertisements }}{24}
\end{aligned}
$$

\section{Statistical analysis}

All statistical analyses were performed with the software IBM SPSS v.20.0, considering results significant at $p<0.05$. The statistical analyses were: descriptive analysis to obtain the frequencies and rates of all variables, and bivariate analysis through contingency charts with a $\chi^{2}$ test, to show the relationship between frequencies, and relative risk; in all tests the significance level was $p<0.05$.

Food advertisements (rows) were classified as CFA, NCFA and OFA, and year (columns) was classified in 2007 and 2013 as TC and in 2013 as GC; it leads to a $3 \times 3$ chart. The analysis of the contingency table by a $\chi^{2}$ test is highly significant $\left(\chi^{2}=\right.$ 197,$181 ;$ d.f. (degrees of freedom) $=4 \mathrm{y} ; p<0.001$ ).

\section{Results}

In this study, $256 \mathrm{~h}$ were recorded from the four Spanish channels the most watched by children. TC (Boing and Disney Channel) had 1.5\% and 1.1\%, and GC (Antena 3 and La Sexta) had 11.5\% and $5.6 \%$ of the total audience respectively.

The frequency of food advertisements per hour in a full time slot was 19 advertisements per hour (adv/h) on TC, and $25 \mathrm{adv} / \mathrm{h}$ on GC (Table I). The majority of food advertisements were about NCFA (54.9\%). On GC the percentage of NCFA was slightly higher than on TC (GC: $57.3 \%$ vs. TC: $52.2 \%$, $p<0.001$ ) (Figure 1).

The most frequently broadcast advertisement on TC was about infant food (excluding infant and toddler milk formulas), 191 times (33\%), followed by dairy products, 136 times (23.5\%). In contrast, on GC, the most shown adverts were about fast food restaurants, 72 times (10.5\%), vitamin and mineral supplements, 71 times (10.4\%), and dairy products, 60 times (8.8\%) (Table II). People watching GC in Spain have a higher relative risk of being exposed to fast food adverts than those watching TC $(R R>1)(2.133,1.398-3.255)$.

Although the percentage of fast food advertisements was high $(4.5 \%$ on TC and $10.5 \%$ on GC, $p<0.001$ ), all of those which were shown on TC (26 out of 26 advertisements) had healthy messages at the end (through fine print or sublimi- 


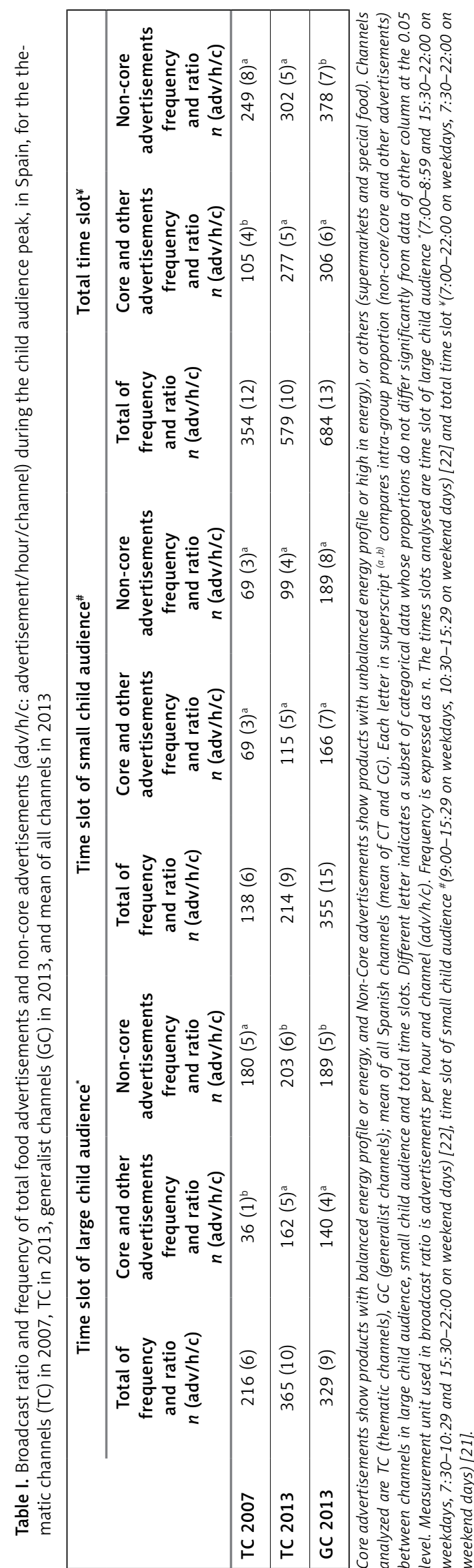

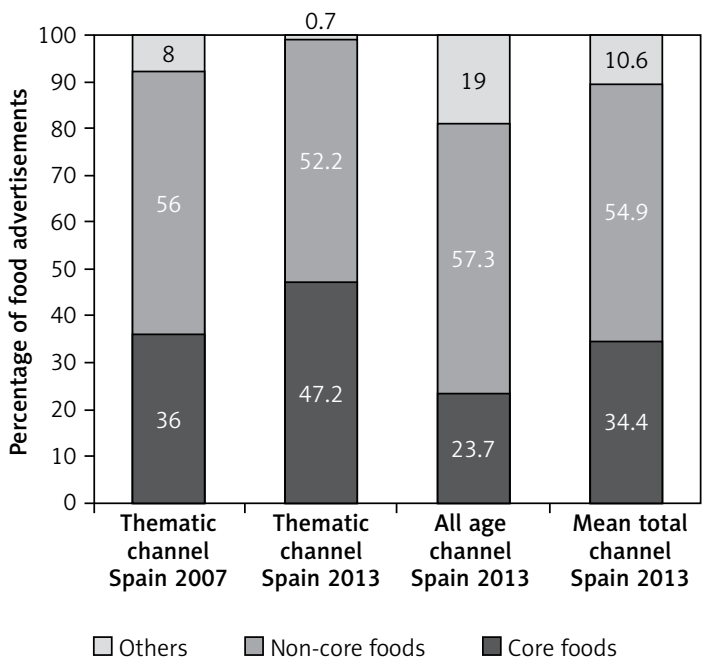

Figure 1. Broadcasting of different groups of advertisements measured in frequency percentage on thematic channels (TC) and generalist channels (GC) (core food, non-core food and others) in Spain in 2007 and 2013. Time slot analysed is 7:00-22:00 on weekdays and 7:30-22:00 on weekend days according with references studied [21]

nal messages). On TC, the publicity about healthy habits was the fourth most shown, with a frequency of 51 times (8.8\%), while on GC, it was the publicity the least shown, with a frequency of 8 times $(1.2 \%)(p<0.001)$ (Table I).

\section{Time slot of food advertising on TV}

On TC during 2013, a total of $63.03 \%$ of food advertisements were shown in children's peak time slots, compared to $36.96 \%$ in children's nonpeak time slots. Moreover, on GC, $48.09 \%$ of food advertisements were broadcast in children's peak time slots, whereas $51.9 \%$ appeared in a different time slot (Table I).

The broadcast ratio of all food advertisements on TC during 2013 was slightly higher in children's peak time slots versus children's nonpeak time slots (10 vs. 9 advertisements per hour and channel $(\mathrm{adv} / \mathrm{h} / \mathrm{c})$ respectively). On the other hand, on GC the broadcast ratio was significantly lower in children's peak time slots compared to different time slots (9 vs. $15 \mathrm{adv} / \mathrm{h} / \mathrm{c}$ respectively) (Table I).

CFA were displayed with higher frequency, $47.2 \%$, on TC in comparison with $23.7 \%$ shown on GC 2013 and $36 \%$ on TC during 2007 ( $p<0.001$ ) (Table II). The broadcasting of NCFA was 180 NCFA compared to 36 CFA in children's peak time slots (proportion 5/1 adv/h/c) on GC 2007, while on TC during 2013 it was 203/162 (6/5 adv/h/c); these differences are significant $(p<0.05)$. By contrast, there were no significant differences between TC and GC during 2013, 189/140 (5/4 adv/h/c) (Table I).

Furthermore, the broadcast ratio of NCFA on TC during 2013 was 6 in children's peak time slots and 
Table II. Type of advertisement and broadcast frequency in children's audiences. Data related to Spain, 2007 and 2013

\begin{tabular}{|c|c|c|c|}
\hline Category & $\begin{array}{c}\text { Broadcast } \\
\text { frequency } \\
\text { on thematic } \\
\text { channels } \\
\text { in } 2007 \\
n(\%)\end{array}$ & $\begin{array}{c}\text { Broadcast } \\
\text { frequency } \\
\text { on thematic } \\
\text { channels } \\
\text { in } 2013 \\
n(\%)\end{array}$ & $\begin{array}{c}\text { Broadcast } \\
\text { frequency } \\
\text { on generalist } \\
\text { channels } \\
\text { in } 2013 \\
n(\%)\end{array}$ \\
\hline \multicolumn{4}{|l|}{ Core food (nutrient dense, low in energy): } \\
\hline Vegetables and vegetable products without added sugar & & $0(0)^{\mathrm{a}}$ & $0(0)^{a}$ \\
\hline Bottled water & & $1(0.2)^{\mathrm{a}}$ & $9(1.3)^{b}$ \\
\hline $\begin{array}{l}\text { Dairy products }(<3 \mathrm{~g} \text { lipids), low-sugar and high- } \\
\text { fibre breakfast cereals }(<20 \mathrm{~g} \text { sugar } / 100 \mathrm{~g} \text { and }<5 \mathrm{~g} \\
\text { fibre/100 g) }\end{array}$ & & $0(0)^{a}$ & $57(8.3)^{b}$ \\
\hline $\begin{array}{l}\text { Low-fat/reduced-fat milk, yogurt, custard ( }<3 \mathrm{~g} \text { fat } / 100 \mathrm{~g} \text { ), } \\
\text { cheese ( }<15 \mathrm{~g} \text { fat } / 100 \mathrm{~g}) \text {, alternatives (including probiotic } \\
\text { drinks), infant food (excluding milk formulas) }\end{array}$ & & $191(33)^{a}$ & $0(0)^{b}$ \\
\hline Fruit and fruit products without added sugar & & $30(5.2)^{\mathrm{a}}$ & $12(1.8)^{\mathrm{b}}$ \\
\hline $\begin{array}{l}\text { Meat and similar products (not crumbed or battered; } \\
\text { including fish, legumes, eggs, nuts, nut products and } \\
\text { peanut butter, excluding sugar-coated and salted nuts) }\end{array}$ & & $0(0)^{a}$ & $22(3.2)^{b}$ \\
\hline $\begin{array}{l}\text { Soups (<2 g lipids/100 g, excluding dehydrates), salads } \\
\text { and sandwiches, frozen meals }(<10 \mathrm{~g} \text { of lipids /ration) } \\
\text { and low-fat savoury sauces (<10 g lipids/100 g) }\end{array}$ & & $0(0)^{a}$ & $22(3.2)^{b}$ \\
\hline $\begin{array}{l}\text { Bread (including high-fibre bread and low-fat crackers), } \\
\text { rice, pasta and noodles }\end{array}$ & & $0(0)^{a}$ & $32(4.7)^{\mathrm{b}}$ \\
\hline Healthy habits & & $51(8.8)^{\mathrm{a}}$ & $8(1.2)^{b}$ \\
\hline Frequency of core food advertisements & $222^{\mathrm{a}}$ & $273^{b}$ & $162^{\mathrm{a}}$ \\
\hline$\%$ Core food advertisements & $22.9 \%$ & $47.2 \%$ & $23.7 \%$ \\
\hline \multicolumn{4}{|l|}{ Non-core food (high content of undesirable nutrients or energy): } \\
\hline Frozen/fried potato products (excluding chips) & & $0(0)^{a}$ & $0(0)^{a}$ \\
\hline Ice cream and iced confections & & $42(7.3)^{\mathrm{a}}$ & $0(0)^{b}$ \\
\hline Fruit juice and fruit drinks & & $7(1.2)^{\mathrm{a}}$ & $15(2.2)^{\mathrm{a}}$ \\
\hline $\begin{array}{l}\text { Crumbed or battered meat and similar products and } \\
\text { high-fat frozen meals ( }>10 \mathrm{~g} \text { of lipids/ration) }\end{array}$ & & $7(1.2)^{\mathrm{a}}$ & $7(1)^{\mathrm{a}}$ \\
\hline Alcohol & & $0(0)^{\mathrm{a}}$ & $1(0.1)^{\mathrm{a}}$ \\
\hline $\begin{array}{l}\text { Cakes, muffins, cookies, high-fat crackers, pies and } \\
\text { pastries }\end{array}$ & & $1(0.2)^{\mathrm{a}}$ & $55(8)^{b}$ \\
\hline $\begin{array}{l}\text { Sugar-sweetened drinks, including soft drinks, cordials, } \\
\text { sports drinks, and flavour additions (including diet } \\
\text { varieties) }\end{array}$ & & $0(0)^{a}$ & $17(2.5)^{\mathrm{b}}$ \\
\hline $\begin{array}{l}\text { Snack foods, including chips, extruded snacks, popcorn, } \\
\text { snack and granola bars, sugar-sweetened fruit and } \\
\text { vegetable products, and sugar-coated or salted nuts }\end{array}$ & & $14(2.4)^{\mathrm{a}}$ & $40(5.8)^{b}$ \\
\hline $\begin{array}{l}\text { High-sugar or low-fibre breakfast cereals ( }>20 \mathrm{~g} \\
\text { sugar/100 g or }<5 \mathrm{~g} \text { fibre/100 g) }\end{array}$ & & $59(10.2)^{\mathrm{a}}$ & $23(3.4)^{b}$ \\
\hline $\begin{array}{l}\text { Whole milk, yoghurt, custard, dairy desserts (> } 3 \mathrm{~g} \text { fat/ } \\
100 \mathrm{~g} \text { ), cheese and similar products }\end{array}$ & & $136(23.5)^{\mathrm{a}}$ & $71(10.4)^{b}$ \\
\hline $\begin{array}{l}\text { High-fat, high-sugar, high-salt spreads (excluding peanut } \\
\text { butter), oils and high-fat savoury sauces }\end{array}$ & & $5(0.9)^{a}$ & $31(4.5)^{b}$ \\
\hline $\begin{array}{l}\text { Chocolate and confectionery (including regular and } \\
\text { sugar-free chewing gum and sugar) }\end{array}$ & & $5(0.9)^{a}$ & $60(8.8)^{b}$ \\
\hline $\begin{array}{l}\text { Fast-food restaurants or meals (including "healthy" } \\
\text { alternatives) }\end{array}$ & & $26(4.5)^{\mathrm{a}}$ & $72(10.5)^{b}$ \\
\hline Frequency of non-core food advertisements & $647^{a}$ & $302^{b}$ & $392^{\mathrm{b}}$ \\
\hline$\%$ Non-core food advertisements & $66.6 \%$ & $52.2 \%$ & $57.3 \%$ \\
\hline
\end{tabular}


Table II. Cont.

\begin{tabular}{|c|c|c|c|}
\hline Category & $\begin{array}{c}\text { Broadcast } \\
\text { frequency } \\
\text { on thematic } \\
\text { channels } \\
\text { in } 2007 \\
n(\%)\end{array}$ & $\begin{array}{c}\text { Broadcast } \\
\text { frequency } \\
\text { on thematic } \\
\text { channels } \\
\text { in } 2013 \\
n(\%)\end{array}$ & $\begin{array}{c}\text { Broadcast } \\
\text { frequency } \\
\text { on generalist } \\
\text { channels } \\
\text { in } 2013 \\
n(\%)\end{array}$ \\
\hline \multicolumn{4}{|l|}{ Others: } \\
\hline Baby and toddler milk formulas & & $4(0.7)^{\mathrm{a}}$ & $2(0.3)^{a}$ \\
\hline Vitamin and mineral supplements & & $0(0)^{\mathrm{a}}$ & $73(10.7)^{b}$ \\
\hline Supermarkets that advertise mostly core food & & $0(0)^{\mathrm{a}}$ & $40(5.8)^{b}$ \\
\hline Tea and coffee & & $0(0)^{\mathrm{a}}$ & $0(0)^{a}$ \\
\hline Supermarkets that advertise mostly non-core food & & $0(0)^{\mathrm{a}}$ & $0(0)^{a}$ \\
\hline $\begin{array}{l}\text { Supermarkets with no specified food (generic } \\
\text { supermarket advertisements or not clearly for core } \\
\text { or non-core foods) }\end{array}$ & & $0(0)^{\mathrm{a}}$ & $15(2.2)^{b}$ \\
\hline Frequency of advertisements for other products & $102^{\mathrm{a}}$ & $4^{b}$ & $130^{c}$ \\
\hline$\%$ Advertisements for other products & $10.5 \%$ & $0.7 \%$ & $19 \%$ \\
\hline Total advertisements & $971^{\mathrm{a}}$ & $579^{\mathrm{b}}$ & $684^{c}$ \\
\hline \% Total advertisements & $100 \%$ & $100 \%$ & $100 \%$ \\
\hline
\end{tabular}

Food advertisements (rows) were classified as core, non-core and other, and year (columns) was classified as 2007, 2013 for TC and 2013 for GC. It leads to a $3 \times 3$ chart that was analysed (through contingency table $\chi^{2}$ test) is significantly higher $\left(\chi^{2}=197,181 ;\right.$ d.f. $=4$ and $p<0.001)$. Each letter in subscript (a,b,c) indicates a subset of categorical data whose proportions do not differ significantly from data of other column at the 0.05 level. Spanish data 2007. Time slots analyzed are 7:00-22:00 on weekdays and 7:30-22:00 on weekend days in accordance with the references studied [21].

$4 \mathrm{adv} / \mathrm{h} / \mathrm{c}$ in children's nonpeak time slots, while on GC in 2013 it was 5 and $8 \mathrm{adv} / \mathrm{h} / \mathrm{c}$ respectively. The broadcasting in children's nonpeak time slots was double on GC versus TC for NCFA, although the difference was not significant (Table I).

\section{Discussion}

We found differences in the broadcast ratio of food advertisements between 2007 and 2013; the broadcasting of food advertising on TV increased from 2007 to 2013 on the TC (6 vs. 10 food ad$\mathrm{v} / \mathrm{h} / \mathrm{c}$, respectively). The broadcasting time in 2013 was similar in 2013 to that in 2007. Nowadays, the broadcasting of NCFA is not better in the children's peak time slots because, although the broadcasting percentage is lower (52.2\% vs. $56 \%$ in 2007), the ratio of NCFA has increased to $+1 \mathrm{adv} /$ $\mathrm{h} / \mathrm{c}$ (a frequency from 180 to 203) compared to that reported in the study performed in Spain in 2007. However, despite this broadcasting of NCFA it would be interesting to know the effects of increasing the broadcasting of CFA on childhood obesity, which has not yet been reported.

Comparing GC and TC in 2013, in children's peak time slots there are no differences between the broadcast ratio of CFA and NCFA. However, in children's nonpeak time slots, the total food advertising and the NCFA were higher on GC than on TC; no significant differences were found in the proportion of CFA and NCFA (Table I).
Regarding time slots of shows, in time slots with a large child audience there are differences in the total number of advertisements shown between 2007 and 2013 (6 vs. 10, adv/h/c, $p<0.05$ ). The situation is similar for time slots with small child audiences; the broadcasting was significantly higher in 2013 than 2013 (6 vs. 9, adv/h/c, $p<0.05$ ).

An important factor to prevent overweight and obesity is to know the effects of the TV programs where food advertisements are shown. Consequently, it would be necessary to control the food publicity shown in children's programmes and to broadcast CFA specially in programmes that are able to attract children's attention; many studies have shown a relationship between cartoons and a major child attention [23, 24], so this could be a good moment to implement healthy nutrition and healthy habits.

Recent longitudinal studies about Saturday morning publicity show that broadcasting frequency of fast food and simple sugar food advertisements has increased in the last years [25]. In fact, broadcasting of CFA in children's peak time slots could be considered as a healthy factor involved in overweight and obesity prevention [26]. In this respect, our study has demonstrated that watching GC in Spain represents a $2.133(95 \% \mathrm{Cl}$ : 1.398-3.255) times relative risk of being exposed to fast food advertisements than watching TC.

The American Academy of Pediatrics recommends that children under 2 years old should not 
watch any TV and that those older than 2 should watch no more than 1 to $2 \mathrm{~h}$ a day of quality programming [27]. Our study shows that children are now exposed to a total of 10 food advertisements per hour, at least 6 of which are of NCFA. In contrast, in 2007 the outcome seemed better, as children were exposed to a total of 6 food advertisements per hour, at least 5 of which were of NCFA. This is an important aspect in view of the fact that now the situation should be better, considering that poor nutrition habits, lack of regular physical activity and unmonitored TV viewing are associated with obesity in children and youth [1]. So, if Spanish children watch TV for $2 \mathrm{~h}$ per day, they will be exposed to 20 food advertisements per day, 12 of which will be of NCFA.

Article 46 of the Spanish law 17/2011, of $5^{\text {th }}$ July, about food security and nutrition, deals with food publicity for people who are younger than 15 years old. It stipulates the negotiation between the competent authorities and the marketing companies to keep the regulation accords on the establishment of good habits and the control of good practices of beverage and food publicity to prevent childhood obesity and other related illnesses in the population. Considering the strong relationship between food advertising and child consumption choices, marketing is an important aspect to prevent obesity during childhood. It is important that the government reviews the laws to control food publicity and lifestyles by decreasing non-core food TV marketing and increasing core food advertising [24]. Therefore, it is clear that the Spanish situation is not ideal, and the reason could be in the application of the approved laws by the government, which seems not to be as strict as necessary to be efficient. However, other authors state that these assumptions have not been conclusively demonstrated and that more research is needed to understand the processes which may differentially affect minority responses to marketing communications [28]. Furthermore, the effectiveness of these measures could probably be enhanced if educational programs are implemented simultaneously to these regulatory guidelines, directed not only at children, but also at families and at the whole community. These programs have been shown to be also very successful when they have been applied to the population [29].

Little attention has been given to how the engineering and marketing of food may interact with possible risk factors to generate brain responses like those to traditional drugs of abuse. If hyperpalatable foods have a fraction of the effects of addictive drugs, the public health significance could be substantial because of the widespread access and exposure to highly marketed, low-cost, nutrient-poor, and calorie-dense products [30]. If the biological effects approach those of addictive drugs, far-reaching policies may be necessary. Given the public health impact, attention should be given to the properties of foods and industry's responsibility in creating them [31]. The WHO emphasizes that marketing of foods and non-alcoholic beverages with a high content of fat, sugar or salt reaches children throughout the world. Efforts must be made to ensure that children everywhere are protected against the impact of such marketing and given the opportunity to grow and develop in a food environment that fosters and encourages healthy dietary choices and promotes the maintenance of healthy weight [32]. In this sense, we consider that healthy neuromarketing could help to transmit in a better way the healthy products, showing them in a more attractive way for children, favouring better food choices, increasing healthy food sales and creating new market opportunities in this area. Taking into account recent research in this area, neuromarketing will help to avoid NCFA and misleading publicity.

Lately, research into the understanding of healthy and unhealthy food choices has been developed by studying the influence of publicity and society in consumers' decisions. Neuroimaging has recently being used in this investigation, but it is still not popular in publications about marketing. This method could be useful to study predictability in people's choices. According to some authors, predictability could have a relationship with the number of times that an item has been previously used and the period of time between publicity exposure and personal choices. Depending on the predictability of choices, different brain regions are stimulated. Unpredictable decisions stimulate brain regions related to silent vocalisation and reward circuitry. Moreover, sex-related differences have been demonstrated [33].

Techniques based on video recording capture an image of the eye from a camera either mounted on head gear worn by the user or mounted remotely. The recent miniaturization of video equipment has greatly minimized the intrusiveness of head-mounted video-based eye trackers [34]. Furthermore, remotely located video-based eye-tracking systems can be completely unobtrusive, although at some cost to the robustness and quality of the eye tracking $[35,36]$.

The prevention programs to control advertising should be geared to make use of the new technologies available such as phones, applications for smart phones, videogames, social networks and other options that easily catch the attention of children.

One limitation of this study is not having registered the advertisements' duration. This aspect is very important because many authors remark that advertisement duration is an important factor in 
child food choices. We could have also evaluated the type of programme where advertisements were broadcasted. These aspects will be analysed in a future study.

Further research is needed on the effects of public policy in the protection of young people against the unhealthy influence of food marketing, especially considering that very little research has directly examined the psychological processes required for defence against newer and less direct forms of marketing [37]. It would be interesting to assess the effects of different social clues for healthy/unhealthy food choices among obese and healthy consumers at the neurophysiologic level. This could shed light on the association of neural circuits of food choices and "real" food choices and hence eating behaviour.

In conclusion, broadcasting frequency of all food advertisements has increased compared to 2007 on TC. It is a consequence of a significant increase in the broadcasting of CFA and NCFA.

Broadcasting of unhealthy food TV advertising is lower today than 6 years ago on TC. However, children's exposure to unhealthy food advertising is worrying in Spain, even more when there is still more exposure to unhealthy than healthy food TV commercials. Broadcasting frequency of non-core publicity on TC was significantly higher in children's peak time slots, while on GC it was significantly lower at the same time slot, despite the new Spanish laws of 2010. Broadcasting frequency of CFA on GC is significantly lower than on TC.

Therefore, at the moment, there is evidence that Spanish laws on food advertising control are still insufficient to avoid unhealthy food publicity on TV and, consequently, to facilitate early prevention of obesity.

\section{Acknowledgments}

This work was partially supported by the NUTRIMENTHE EU Project, Grant agreement no. 212652 and the University of Granada, Granada, Spain.

\section{Conflict of interest}

The authors declare no conflict of interest.

\section{References}

1. Anderson PM, Butcher KF. Childhood obesity: trends and potential causes. Future Children 2006; 16: 19-45.

2. Alwan A. Global status report on noncommunicable diseases 2010. World Health Organization 2011.

3. Lobstein T, Baur L, Uauy R. Obesity in children and young people: a crisis in public health. Obes Rev 2004; 5 (Suppl. 1): 4-85.

4. Ogden CL, Carroll MD, Kit BK, Flegal KM. Prevalence of childhood and adult obesity in the United States, 20112012. JAMA 2014; 311: 806-14.
5. Ogden CL, Carroll MD, Curtin LR, Lamb MM, Flegal KM. Prevalence of high body mass index in US children and adolescents, 2007-2008. JAMA 2010; 303: 242-9.

6. Serra-Majem L, Aranceta Bartrina J, Pérez-Rodrigo C, Ribas-Barba L, Delgado-Rubio A. Prevalence and determinants of obesity in Spanish children and young people. Br J Nutr 2006; 96 (Suppl. 1): S67-72.

7. Gable S, Chang Y, Krull JL. Television watching and frequency of familiy meals are predictive of overweight onset and persistence in a national sample of school-age children. J Am Diet Assoc 2007; 107: 53-61.

8. Matthews AE. Children and obesity: a pan-European project examining the role of food marketing. Eur J Publ Health 2008; 18: 7-11.

9. Lobstein T, Dibb S. Evidence of a possible link between obesogenic food advertising and child overweight. Obes Rev 2005; 6: 203-8.

10. Kunkel D, Wilcox BL, Cantor J, Palmer E, Linn S, Dowrick P. Report of the APA task force on advertising and children. American Psychological Association 2004; 40.

11. Bruce AS, Lepping RJ, Bruce JM, et al. Brain responses to food logos in obese and healthy weight children. J Pediatr 2013; 162: 759-64.

12. De Araujo IE, Oliveira-Maia AJ, Sotnikova TD, et al. Food reward in the absence of taste receptor signaling. Neuron 2008; 57: 930-41.

13. Senior C. Beauty in the brain of the beholder. Neuron 2003; 38: 525-8.

14. Erk S, Spitzer M, Wunderlich AP, Galley L, Walter H. Cultural objects modulate reward circuitry. Neuroreport 2002; 13: 2499-503.

15. McClure SM, Li J, Tomlin D, Cypert KS, Montague LM, Montague PR. Neural correlates of behavioral preference for culturally familiar drinks. Neuron 2004; 44: 379-87.

16. Montgomery KC, Chester J. Interactive food and beverage marketing: targeting adolescents in the digital age. J Adolesc Health 2009; 45: S18-29.

17. Mateu NA. Advertising and promotion of healthy eating habits in the law on food safety and nutrition. Administrative Today 2013 (5): 1.

18. Ekeland E, Heian F, Hagen K, Coren E. Can exercise improve self esteem in children and young people? A systematic review of randomised controlled trials. $\mathrm{Br}$ J Sports Med 2005; 39: 792.

19. Fulkerson JA, Strauss J, Neumark-Sztainer D, Story M, Boutelle K. Correlates of psychosocial well-being among overweight adolescents: the role of the family. J Consult Clin Psychol 2007; 75: 181-6.

20. Kyriazis I, Rekleiti M, Saridi M, et al. Prevalence of obesity in children aged 6-12 years in Greece: nutritional behaviour and physical activity. Arch Med Sci 2012; 8: 859-64.

21. Kelly B, Halford JC, Boyland EJ, et al. Television food advertising to children: a global perspective. Am J Publ Health 2010; 100: 1730-6.

22. Kelly B, Hattersley L, King L, Flood V. Persuasive food marketing to children: use of cartoons and competitions in Australian commercial television advertisements. Health Promotion Intern 2008; 23: 337-44.

23. Neeley SM, Schumann DW. Using animated spokes-characters in advertising to young children: does increasing attention to advertising necessarily lead to product preference? J Advert 2004; 33: 7-23.

24. Holt DJ, Ippolito PM, Desrochers DM, Kelley CR. Children's exposure to TV advertising in 1977 and 2004: information for the obesity debate: Federal Trade Commission, Bureau of Economics 2007. 
25. Byrd-Bredbenner C. Saturday morning children's television advertising: a longitudinal content analysis. Fam Consum Sci Res J 2002; 30: 382-403.

26. Handsley E, Mehta K, Coveney J, Nehmy C. Regulatory axes on food advertising to children on television. Aust New Zealand Health Policy 2009; 6: 1.

27. Brown A. Media use by children younger than 2 years. Pediatrics 2011; 128: 1040-5.

28. Williams JD, Lee WN, Henderson GR. Diversity issues in consumer psychology. Lawrence Erlbaum Associates, New York 2008.

29. Bammann K, Peplies J, Pigeot I, Ahrens W. [IDEFICS: a multicenter European project on diet-and lifestyle-related disorders in children]. Medizinische Klinik (Munich, Germany: 1983) 2007; 102: 230-5.

30. Gearhardt AN, Grilo CM, DiLeone RJ, Brownell KD, Potenza MN. Can food be addictive? Public health and policy implications. Addiction 2011; 106: 1208-12.

31. Brownell KD, Kersh R, Ludwig DS, et al. Personal responsibility and obesity: a constructive approach to a controversial issue. Health Affairs 2010; 29: 379-87.

32. Organization $\mathrm{WH}$. Set of recommendations on the marketing of foods and non-alcoholic beverages to children 2010.

33. Braeutigam S, Rose SP, Swithenby SJ, Ambler T. The distributed neuronal systems supporting choice-making in real-life situations: differences between men and women when choosing groceries detected using magnetoencephalography. Eur J Neurosci 2004; 20: 293-302.

34. Babcock JS, Pelz JB. Building a lightweight eyetracking headgear. In: Proceedings of the 2004 symposium on Eye tracking research \& applications 2004. ACM 2004; 109-14.

35. Haro A, Flickner M, Essa I. Detecting and tracking eyes by using their physiological properties, dynamics, and appearance. In: Computer Vision and Pattern Recognition, 2000. Proceedings. IEEE Conference on; 2000: IEEE 2000; $163-8$.

36. Morimoto $\mathrm{CH}$, Mimica MR. Eye gaze tracking techniques for interactive applications. Computer Vision and Image Understanding 2005; 98: 4-24.

37. Harris JL, Brownell KD, Bargh JA. The food marketing defense model: integrating psychological research to protect youth and inform public policy. Soc Issues Policy Rev 2009; 3: 211-71. 